\title{
Processo de Endividamento Brasileiro: uma Análise de Sustentabilidade para o Século XXI
}

The Brazilian Indebtedness Process: an Analysis of Sustainability for the 21st Century

\author{
Ricardo de Souza Tavares ${ }^{a}$ \\ Iuna Lamb Scheffler ${ }^{b}$ \\ Gabriel Sallum Pentagna Guimarães ${ }^{c}$
}

\begin{abstract}
Resumo: O debate acerca do processo de endividamento público tem ganhado força nos últimos anos. De forma que se faz necessário verificar de modo técnico a atual situação fiscal do país, assim como avaliar sua evolução. Para tanto do ponto de vista de teoria econômica foi utilizada a hipótese clássica do orçamento equilibrado, com auxílio de uma abordagem econométrica baseada em testes de estacionaridade e cointegração das variáveis fiscais, contemplando o período de 2000 a 2017. Os resultados apontam que o déficit público tem apresentado um comportamento não estacionário, além da ausência de cointegração entre receitas e despesas do governo.
\end{abstract}

Palavras-chave: Gestão fiscal, dívida pública, sustentabilidade fiscal.

Classificação JEL: E61, E62, H63

\begin{abstract}
The discussion over the public debt process has been gaining strength in recent years. Therefore, it is necessary to verify technically the current fiscal situation of the country, as well as to evaluate its evolution. From the economic theory point of view, the classical balanced budget hypothesis was used, with the aid of an econometric approach based on stationarity tests and cointegration of fiscal variables, covering the period from 2000 to 2017 , whose results indicate that the public deficit has presented a non-stationary behavior, besides the absence of cointegration between government revenues and expenses.
\end{abstract}

Keywords: Fiscal Management, public debt, fiscal sustainability.

\footnotetext{
${ }^{\text {a }}$ Mestre em Economia pela UFRGS, Professor do Centro Universitário U-VERSE, Economista da UFAC. E-mail: ricardo.tavares@ufac.br

${ }^{\mathrm{b}}$ Mestre em Economia pela UFRGS. E-mail: iuna.ls@hotmail.com

${ }^{\mathrm{c}}$ Mestre em Economia pela UFRGS. E-mail: gabrielsallumpentagna@gmail.com
} 


\section{Introdução}

A dívida pública e o seu processo de aceleração têm tomado grande espaço no debate econômico e acadêmico atual. O governo vem se esforçando na tentativa de implementação de uma série de políticas de austeridade fiscal, tais como aumento de impostos, contenção de despesas e algumas reformas, caso da previdência, que visam a contenção da trajetória explosiva do déficit público e uma possível reversão desse quadro a longo prazo. No final de 2017, a dívida pública bruta atingiu $\mathrm{R} \$ 4,85$ trilhões, o que equivale a $74 \%$ do PIB, segundo previsões do $\mathrm{FMI}^{1}$ essa relação pode chegar a aproximadamente $94 \%$ do produto em 2020, razão bastante elevada para países em desenvolvimento. Diversos estudos, tais como o de Reinhart e Rogoff (2010) e Checherita e Rother 2012, demonstram que níveis altos da razão dívida/produto podem afetar o crescimento econômico, o que dificulta ainda mais a tarefa de estabilização fiscal do governo.

Ainda sobre a situação fiscal atual, as contas do setor público consolidado ${ }^{2}$ apresentaram um déficit primário de R\$110,58 bilhões, ou 1,7\% do produto em 2017, resultado que poderia ser ainda pior não fossem as receitas extraordinárias advindas de privatizações e de concessões. Apesar de estar dentro da nova lei do teto dos gastos $^{3}$, o resultado é bastante expressivo e elucida a dificuldade de se alcançar uma situação fiscal mais equilibrada.

Além disso, o montante despendido com o pagamento de juros nominais da dívida pública foi superior a $\mathrm{R} \$ 400$ bilhões no acumulado do ano, o que corresponde a mais de $6 \%$ do PIB. Se somado o déficit primário aos juros nominais, chega-se a um déficit nominal de cerca 511 bilhões de reais, o que representa um aumento no estoque da dívida pública nominal de mais de meio trilhão de reais apenas em 2017. Sendo assim, fica mais do que evidente a preocupação e a relevância da dívida pública na conjuntura atual.

No que tange ao estudo da dinâmica da dívida pública e da solvência fiscal da economia brasileira, alguns estudos empíricos anteriores apontaram para a sustentabilidade do processo de endividamento brasileiro, como é o caso de Pastore (1994) que analisou a solvência das contas públicas para os anos de 1974 a 1989, e Silva e Gamboa (2011) que estenderam sua pesquisa para os anos de 1986 a 2006. Porém, já se passaram alguns anos desde que tais estudos foram realizados, havendo, no período, mudanças conjunturais, políticas e institucionais, por consequência, mudanças nos processos de tomada de decisões da autoridade fiscal que podem ter

\footnotetext{
${ }^{1}$ Previsão divulgada junto ao International Monetary Fund - World Economic Outlook

Database/Historical Public Debt Database, disponível em: http://www.imf.org/en/Datadata.

${ }^{2}$ As contas do setor público consolidado são compostas pelos resultados do Governo Federal, dos estados, dos municípios e pelos resultados das estatais.

${ }^{3}$ Emenda Constitucional 95/2016.
} 
alterado a dinâmica do endividamento público. Dessa forma, torna-se propícia uma reavaliação da sustentabilidade do processo de endividamento brasileiro, com intuito de verificar de modo técnico a atual situação fiscal do país, compará-la a períodos anteriores e avaliar sua evolução.

Em relação aos aspectos metodológicos referentes à análise da estrutura de solvência de uma economia, recorre-se à hipótese do orçamento equilibrado, ou regime fiscal ricardiano, no qual se um governo pratica uma política fiscal sustentável (ricardiana) terá o valor total do seu estoque de dívida igual ao valor descontado dos superávits futuros, o que será elucidado de modo melhor na seção 3. Essa é uma suposição clássica e sustentará toda a análise do ponto de vista da teoria econômica.

Quanto à análise econométrica, em um primeiro momento será avaliada a estacionaridade da série dos déficits públicos (ou as primeiras diferenças da dívida pública) e as implicações disso para a sustentabilidade fiscal. Em seguida, será construído um modelo econométrico para avaliação da cointegração entre receitas e gastos do governo, de forma que os seus resultados levem a uma conclusão semelhante à primeira análise, uma vez que a relação de longo prazo entre essas variáveis (cointegração entre receitas e gastos) implica a estacionariedade do déficit. Para tanto, serão utilizadas algumas ferramentas econométricas, tais como funções de autocorrelação, testes de raiz unitária e metodologias para avaliação de cointegração das variáveis fiscais.

Apesar de se esperar que ambas análises apontem para o mesmo resultado, elas se complementam e se confirmam, sendo uma abordagem interessante a se fazer para o caso em estudo. $O$ período a ser analisado cobrirá todo processo de endividamento brasileiro do século XXI, de janeiro de 2000 a dezembro de 2017. Tornando possível a comparação dos resultados com outros estudos feitos sob a mesma temática em períodos anteriores.

Além dessa breve introdução, o artigo conta com uma curta revisão de literatura na segunda seção; a seção seguinte é destinada a apresentação da metodologia do ponto de vista da teoria econômica, além dos procedimentos econométricos; a quarta seção se destina à apresentação e à discussão dos resultados; e, por fim, são feitas algumas considerações finais.

\section{Sustentabilidade da Dívida Pública - Estudos Empíricos}

O debate sobre a solvência de regimes fiscais adotados por economias ao redor do mundo vem de forma recorrente chamando a atenção do público acadêmico e de demais agentes econômicos. Com passar do tempo, alguns conceitos e metodologias foram desenvolvidos a fim de analisar a sustentabilidade do processo de endividamento público e a trajetória das variáveis fiscais dos países. 
Os estudos seminais nesse campo foram produzidos por Hamilton e Flavin (1986), que testaram a sustentabilidade do déficit fiscal americano em um período de mais de 30 anos, utilizando para isso testes de raiz unitária aplicados às séries de dívida pública e de déficit primário. Devido a sua pesquisa, os autores concluíram a validação da hipótese de sustentabilidade do regime fiscal adotado, mesmo não levando em conta o gasto do governo com a rolagem da dívida, aspecto incluído na análise de Trehan e Walsh (1988), cujos resultados também apontaram para solvência fiscal americana.

O trabalho de Trehan e Walsh (1988) observa a sustentabilidade fiscal de uma economia por meio da relação de longo prazo entre gastos e arrecadação total do governo. Incorporando essa tendência, Hakkio e Rush (1991) e Bohn (1991) realizaram estudos em que testaram cointegração entre dispêndio e arrecadação do governo de modo a satisfazer a restrição orçamentária intertemporal. Todas essas análises levaram em conta o gasto do governo com pagamento de juros; porém, Haug (1995) se apoiou na hipótese de que a condição suficiente para que o regime fiscal tenha um comportamento ricardiano é a cointegração entre o superávit primário e o estoque total da dívida defasado em um período.

Uma outra abordagem é a proposta por Bohn (1998), que elaborou uma nova metodologia para análise de solvência fiscal de um país, na qual um governo pratica uma política fiscal ricardiana, ou seja, sua restrição orçamentária intertemporal está em equilíbrio numa situação em que o superávit primário reage de modo positivo a elevações na razão dívida/produto. Em Bohn (2007), o autor questiona a necessidade das hipóteses clássicas de cointegração e de estacionaridade para satisfação da restrição orçamentária intertemporal do governo, e, de modo alternativo, analisa a sustentabilidade do processo de endividamento público utilizando uma função de reação do governo. No seu trabalho posterior, Bohn (2008), encontra evidências favoráveis à sustentabilidade da dívida pública dos Estados Unidos utilizando a abordagem clássica e a sua nova especificação da função de resposta do governo para um período de 210 anos.

Outro fator que impulsionou o debate acerca da situação fiscal dos países foi a grande crise econômica vivenciada a partir de 2008, dado seu reflexo global e seus impactos diretos nos estoques de dívidas públicas. Interessados nessa onda de aumento do endividamento público, Ghosh et al. (2013) investigaram o quanto a dívida poderia aumentar sem comprometer a situação de estabilidade fiscal dos países. Para tanto, analisaram um grupo de 23 países desenvolvidos e, utilizando um modelo estocástico de inadimplência soberana, concluíram que um governo pode exibir fadiga fiscal, isto é, sua capacidade de realizar superávits primários pode não conseguir acompanhar a variação de seu estoque de dívida pública. Além disso, estimaram limites para a razão dívida/produto, a partir dos quais o movimento de aceleração da acumulação de dívida pública pode não ser mais reversível. 
Com o objetivo de compreender os impactos de sequências explosivas de déficit público sobre as demais variáveis econômicas, Checherita e Rother (2012), ao analisarem a relação dívida/produto para 12 países da zona do Euro, evidenciaram que há relação entre o aumento do estoque da dívida e o crescimento do produto. No entanto, esse processo não é linear e se torna mais forte quando o nível de dívida pública ultrapassa um determinado limite, que pode variar de acordo com as peculiaridades de cada economia. De modo geral, os impactos podem ser significativos quando a dívida pública chega a 70\% do Produto Interno Bruto (PIB), e se acentuariam ainda mais quando a dívida passasse a representar de $90 \%$ a $100 \%$ do produto. Além deles, Reinhart e Rogoff (2010), e Woo e Kumar (2015), encontram evidências semelhantes para níveis acima de 90\% da relação dívida/produto.

No caso de economias emergentes, Tanner e Samake (2008) avaliaram a sustentabilidade da política fiscal sob incerteza para Brasil, México e Turquia. Para tanto, modelaram um vetor autorregressivo (VAR) para cada um dos países em que incluíram variáveis econômicas com a finalidade de mensurar as parcelas de aumento do estoque de dívida pública que estariam sendo determinadas por ações de políticas fiscais definidas pelos autores como insustentáveis, por choques adversos, ou por ambos. Além disso, estimaram o superávit primário necessário para se atingir a sustentabilidade da dívida pública em uma análise probabilística com $90 \%$, com $75 \%$ ou com $50 \%$ de confiança para cada uma das economias e encontram evidências distintas do superávit necessário para cada caso nos cinco anos posteriores ao seu estudo para estabilização e redução da razão dívida/produto.

No contexto de estudos que abordaram especificamente o caso brasileiro, temse como precursor Pastore (1994) que utilizou uma metodologia que examina a estacionariedade da primeira diferença do estoque da dívida pública brasileira, isto é, o déficit público, para o período que vai de 1974 a 1989. O autor conclui que o estoque da dívida pública total, que inclui a dívida interna e externa, era estacionário, portanto, o processo de endividamento é sustentável. No entanto, o autor faz a ressalva que a sustentabilidade só foi possível graças a uma política monetária passiva, que alavancou a senhoriagem como relevante forma de arrecadação do governo, gerando assim um regime fiscal solvente.

A próxima a avaliar a solvência do regime fiscal brasileiro é Rocha (1997), porém com uma mudança na abordagem utilizada. Num primeiro momento, a autora analisa o processo gerador da dívida interna e, no passo seguinte, testa a cointegração entre receitas e despesas fiscais para um período que vai do início de 1980 até o meio de 1993. A autora encontra evidência empírica da existência do equilíbrio orçamentário intertemporal do governo para o período seguinte ao congelamento dos ativos financeiros (adotado no Governo Collor); anteriormente a dívida apresentava comportamento instável. Pastore (1994) destaca a importância 
da senhoriagem na composição da receita do governo para satisfação da restrição orçamentária intertemporal do governo para o período em análise.

Já Issler e Lima (1998) questionam qual seria o melhor caminho para a manutenção de um orçamento equilibrado, via-se aumento de receita ou de cortes de gastos governamentais. Pergunta que se justifica, uma vez que havendo aumento nos gastos públicos presentes, sem contrapartida na arrecadação, para que ocorra a manutenção de um regime de orçamento equilibrado, tal aumento de dispêndios deve ser compensado futuramente com a redução de gastos ou aumento de tributos. Os autores utilizaram técnicas de avaliação de raiz unitária e de cointegração para testar o equilíbrio de longo prazo das finanças públicas brasileiras para um período que vai de 1947 a 1992, concluindo que o governo conseguiu manter a sustentabilidade da dívida no período valendo-se de aumento nos tributos e de senhoriagem para compensar os momentos de desequilíbrios fiscais.

Luporini (2000) faz uma análise da sustentabilidade fiscal brasileira utilizando dados da dívida pública mobiliária a partir do ano de 1965, quando foi realizada uma grande reforma no sistema financeiro nacional, até o ano de 1996. Tomando a série como um todo, a autora conclui pela validade da hipótese de sustentabilidade do regime fiscal, porém encontra evidências para quebra do equilíbrio fiscal se analisado separadamente o período que vai de 1981 a 1996. No entanto, não leva em conta a receita obtida com a emissão de moeda em sua análise, o que poderia mudar esse quadro, dado os elevados níveis de inflação ocorridos nesse período mais curto.

Uma abordagem alternativa para investigação da dinâmica da dívida pública foi a desenvolvida por Garcia e Rigobon (2004), que, por meio de uma visão de gerenciamento de risco, construíram um modelo para análise da solvência fiscal. Os autores utilizaram dados dos estoques brutos e líquidos de dívida externa e interna para desenvolver um modelo de vetores autorregressivos com aplicação em países emergentes. Tomando o caso brasileiro para demonstração empírica, chegam a conclusão de que o comportamento do regime fiscal é sustentável, dadas algumas ressalvas sobre as possíveis trajetórias da política fiscal.

Lima e Simonassi (2005) também estudaram a situação brasileira. Além de incorporar a possibilidade de que o déficit público não seguiria um processo linear, investigaram a importância da receita com emissão de moeda (senhoriagem) na busca pela obtenção de equilíbrio fiscal. Seus resultados evidenciaram a existência de alguns períodos de estabilização fiscal tardia ${ }^{4}$ e que a senhoriagem despendia papel fundamental para estabilização no período em análise.

\footnotetext{
${ }^{4}$ A estabilização fiscal tardia ocorre quando grupos se opõem a ações de estabilização fiscal, uma vez que são mais atingidos por essas medidas, retardando e dificultando as políticas necessárias à eliminação de trajetórias não sustentáveis de déficit público. Para mais detalhes, ver Alesina e Drazen (1991).
} 
Em Gamboa (2005), a análise foi baseada em dados que se iniciam na época do Império (1823) e que vão até o ano de 2005. Por meio de testes de cointegração com a inclusão de dummies de default e de renegociação da dívida, o autor evidencia a oscilação entre períodos de autêntica sustentabilidade, períodos em que o equilíbrio intertemporal só é atingido via default e outros nos quais só se atinge o equilíbrio fiscal com auxílio da senhoriagem.

Ainda, segundo Silva e Gamboa (2011), que analisaram a solvência fiscal brasileira para o período de 1986 a 2006 através de uma análise de cointegração entre despesas e receitas (com e sem senhoriagem) do governo federal, o processo de endividamento público seguia um regime ricardiano considerando ou não senhoriagem para um período mais recente, ou seja, era solvente com ou sem o acréscimo da senhoriagem à receita total do governo. O que é bem compreensível tendo em vista o controle da inflação ocorrido no período após a implementação do Plano Real, que diminuiu drasticamente a receita com emissão de moeda.

No presente artigo serão utilizadas metodologias clássicas, como às evidenciadas anteriormente, para análise da sustentabilidade do processo de endividamento brasileiro. Além disso, se recorrerá às conclusões encontradas nesses trabalhos para complementar a avaliação dos fenômenos mais recentes no tocante à trajetória da dívida pública.

\section{Teoria Econômica e Arcabouço Econométrico}

O financiamento do déficit da Administração Pública de uma determinada economia se dá via emissão de títulos da dívida, que podem ser utilizados para captação interna e/ou externa, ou por meio da senhoriagem, isto é, pela receita obtida via emissão de moeda. Na prática acontece uma combinação dessas duas formas, especialmente quando o país possui moeda própria.

No entanto, segundo Sargent e Wallace (1981) e Woodford (2001) a realização de seguidos déficits fiscais pode trazer à tona a perspectiva de insolvência, ou de um regime fiscal não ricardiano, acarretando graves consequências de âmbito macro e microeconômico. Uma sequência duradoura de déficits além de aumentar o estoque da dívida pública, e, por consequência, o serviço da dívida impacta outras variáveis, dificultando a reversão desse quadro.

Então, o primeiro passo para a análise de sustentabilidade da dívida pública é entender a dinâmica do processo de endividamento, os procedimentos econométricos que permitem fazer inferências sobre essa dinâmica e, por fim, a realização empírica da metologia proposta. 


\subsection{Dinâmica da Dívida Pública}

Algumas variáveis importantes explicam a dinâmica da dívida pública e são comumente definidas na literatura acerca do tema, como pode ser visto em Walsh (2010) e em Silva e Gamboa (2011). Tais variáveis são definidas em dois grupos: fiscais e monetárias. As primeiras são caracterizadas por serem instrumentos de política fiscal, sendo elas: $B_{t}$ que se trata da dívida pública real no período $t, D_{t}$ que é a despesa do governo livre de serviços financeiros no período t e $T_{t}$ que corresponde a receita total do governo em $t$; e por fim temos a variáveis monetárias: a taxa real de juros (r) e a senhoriagem $\left(S_{t}\right)$.

Definidas as variáveis, note que sempre que o governo se encontra em uma situação de déficit primário (se $D_{t}>T_{t}$ ) é necessária a captação de recursos por parte do governo via emissão de títulos ou via emissão de moeda (senhoriagem). A primeira alternativa gera elevação do estoque real da dívida pública para o período seguinte, $B_{t+1}$, de forma que maiores serão os gastos com pagamento de juros em $\mathrm{t}+\mathbf{1}\left(r B_{t+1}>r B_{t}\right)$. Já a emissão de moeda gera pressões inflacionárias à economia. As variações no estoque da dívida pública, se excetuada a senhoriagem, são dadas por:

$$
B_{t+1}-B_{t}=\left(D_{t}+r B_{t}\right)-T_{t}
$$

Tal equação pode ser compactada se somada a despesa fiscal do governo $\left(D_{t}\right)$ ao pagamento dos juros da dívida pública $\left(r B_{t}\right)$, gerando a nova variável gasto total do governo $\left(G_{t}\right)$ :

$$
B_{t+1}-B_{t}=G_{t}-T_{t}
$$

A inclusão da senhoriagem alterará a equação (2) para:

$$
D P_{t}=B_{t+1}-B_{t}=G_{t}-R_{t}
$$

com $R_{t}=T_{t}+S_{t}$ e sendo $D P_{t}$ é do déficit público descontada a senhoriagem. Essa equação define a necessidade real de financiamento do setor público.

De modo intuitivo, a senhoriagem pode ser definida como a receita obtida pelo governo com a emissão de moeda, ou, ainda, como a diferença entre o valor de face e os custos envolvidos no processo de emissão de moeda. Formalmente, segundo Walsh (2010), a senhoriagem é dada por:

$$
S_{t}=\frac{H_{t}-H_{t-1}}{P_{t}}=h_{t}-h_{t-1}+\frac{\pi_{t}}{1+\pi_{t}} h_{t-1}
$$

em que $H_{t}-H_{t-1}$ é a variação da base monetária de t-1 para t, $P_{t}$ é o nível de preços em $\mathrm{t}, h_{t}$ é o estoque real de moeda no período $t$ e $\pi_{t}$ é a inflação medida por algum índice de preços em $t$. 
Em relação à equação 3 , note que o déficit público $\left(D P_{t}\right)$ é dado pela diferença entre gasto total e receita total da Administração Pública. Além disso, receita total é dada pela arrecadação total do governo $\left(T_{t}\right)_{5}$ acrescida da senhoriagem. De forma que quando há déficit público, ou seja, $D P_{t}$ é positivo, o financiamento deste ocorre necessariamente via emissão de dívida pública; portanto, há uma variação positiva no estoque da dívida de um ano para o outro.

Um processo de endividamento público pode ser considerado sustentável se obedecer a uma política fiscal ricardiana. Segundo Woodford (1995), um regime fiscal é dito ricardiano se a autoridade fiscal segue uma sequência de gastos e de arrecadação fiscal de modo que o valor presente consolidado da restrição intertemporal do governo seja equilibrado; caso contrário, o regime fiscal é dito nãoricardiano.

Ainda, a equação (3) serve como base ao estudo da sustentabilidade da dívida pública. Pois, para que ocorra uma política fiscal ricardiana, a série de déficit público deve ser estacionária, ou, ainda, as primeiras diferenças da dívida pública têm de ser estacionárias. O que equivale a afirmar que há uma relação de equilíbrio a longo prazo entre receita total e gasto total do governo.

Sendo assim, há duas formas de se analisar a sustentabilidade da dívida pública: a primeira se dá via análise de estacionariedade da série de déficits públicos; se ela for estacionária, há evidencias de que o regime fiscal é sustentável ou seja ricardiano, pois a dívida pública seria, nesse caso, estacionária em primeiras diferenças; já a segunda alternativa é feita por meio de uma análise de cointegração entre gastos e receitas totais reais, que também corroboraria a hipótese de sustentabilidade fiscal. Logo, serão feitas as duas análises em relação à situação fiscal. Espera-se obter resultados semelhantes para ambas, pois não seria possível a ausência de cointegração e de estacionáriedade da série de déficits e vice-versa.

Sob uma ótica intertemporal, a equação (3) pode ser reescrita como:

$$
B_{t}=\sum_{i=0}^{\infty} \beta^{i} E_{t}\left(R_{t+i}-G_{t+i}\right), \quad \beta^{i}=\frac{1}{1+r}
$$

Para que o processo de endividamento seja sustentável, a política fiscal deve respeitar a restrição orçamentária intertemporal dada pela equação (5). Ela é condição necessária e suficiente à existência de uma política fiscal ricardiana. A satisfação dessa restrição implica que o estoque da dívida pública equivale ao valor descontado dos superávits futuros. Esta é a hipótese do orçamento equilibrado que será testada na aplicação empírica. Na qual se o estoque presente da dívida for igual ao valor da soma da série de resultados positivos futuros, independentemente do seu nível de endividamento, o governo conseguirá arcar com o pagamento de toda sua

${ }^{5} T_{t}$ desconsidera a receita com a emissão de moeda. 
dívida emitida até o presente e, então, estaria em um regime sustentável em termos fiscais.

Além disso, a equação (5) satisfaz a condição No-Ponzi-Game, em que um governo não pode se financiar via endividamento de forma perpétua. Tal condição é dada pela equação a seguir:

$$
\lim _{n \rightarrow \infty} E_{t}\left(B_{t+n}\right)=0
$$

Assim, o que se propõe é uma análise simples de estacionariedade da série de déficit público, que, se comprovada, evidenciaria a existência de um regime ricardiano de política fiscal. Além da construção de um modelo econométrico para avaliação de cointegração entre as receitas e os gastos totais do governo, de modo a confirmar o resultado da análise de estacionariedade anterior.

\subsection{Análise de Cointegração - Receitas e Gastos do Governo}

O modelo econométrico desenvolvido para testar a hipótese da cointegração entre receitas e despesas do governo pode ser construído, conforme Silva e Gamboa (2011), levando em conta o processo estocástico conjunto de geração de dados referentes aos gastos do governo e à arrecadação total, que são representados pelo vetor $Y_{t}$, de forma condicional à taxa real de juros. A função densidade de probabilidade (FDP) condicional conjunta $\Phi$ pode fazer a representação genérica de tal processo, como se vê a seguir:

$$
\Phi\left(Y t \mid r_{t}\right)
$$

em que $Y_{t}=\left(G_{t}, R_{t}\right)$.

Se satisfeita a condição de estacionariedade da taxa real de juros, ou seja, se ela for $\mathrm{I}(\mathrm{o})$, valerá a seguinte relação ${ }^{6}$ :

$$
\Phi\left(Y t \mid r_{t}\right) \approx \Phi(Y t)
$$

Caso as variáveis contidas no vetor Y não sejam estacionarias, porém tenham suas primeiras diferenças estacionárias, pode-se afirmar que tais variáveis são integradas de primeira ordem (I(1)). Uma análise de cointegração dessas variáveis pode evidenciar uma relação de longo prazo entre elas. Se a hipótese de cointegração for confirmada implicará que o déficit público é estacionário, então o governo segue um regime fiscal ricardiano. Note que as conclusões acerca do resultado da análise de cointegração devem ser equivalentes às obtidas no estudo estacionariedade do déficit público (ou as primeiras diferenças dívida pública).

\footnotetext{
${ }^{6}$ Com essa condição pode-se supor que a taxa real de juros é constante.
} 
O estudo de cointegração é feito a partir do vetor autorregressivo (VAR) de ordem (p):

$$
Y_{t}=\alpha_{0}+\alpha_{1} t+\sum_{i=1}^{p} A_{i} Y_{t-i}+\varepsilon_{t}
$$

em que $\alpha_{0}$ é o vetor de parâmetros lineares do VAR (p); $\alpha_{1}$ é o vetor de parâmetros de tendência determinística; $A_{i}$ é matriz de coeficientes para todo $i \leq p, i>0$; $\varepsilon_{t} \sim N I I D(0, \Theta)$ é o vetor de resíduos (independentes e normalmente distribuídos) $\operatorname{com} \Theta=I \sigma^{2}$, de modo que os resíduos sejam ruído brancos ${ }^{7}$.

Nesse caso, para as duas variáveis $(n=2)$ contidas em $Y$ estacionarias em diferenças (I(1)), pode ser construído um VAR (p) a fim de se analisar a relação de longo prazo entre elas por meio de um vetor de cointegração $(n-1=1)$.

A equação (9) permite então remodelar o VAR (p), juntamente a seus componentes determinísticos. Antes de iniciar o processo de construção do modelo autorregressivo é importante verificar a ordem de integração das variáveis. Depois disso, deve-se fazer uso dos critérios de seleção de defasagens e testar a presença de componentes determinísticos, a fim de se obter uma boa especificação para o modelo. Se as séries utilizadas no modelo forem I(1), ele pode ser reescrito da seguinte forma:

$$
\Delta Y_{t}=\delta_{0}+\delta_{1} t+\mathrm{o}_{p} Y_{t-1}+\sum_{i=1}^{p-1} \mathrm{o}_{i} \Delta Y_{t-i}+\varepsilon_{t}
$$

em que $\Delta$ é a primeira diferença da variável a qual acompanha; $\delta_{0}$ é um vetor de constantes; $\delta_{1}$ é o vetor de coeficientes de tendência determinística, os dois últimos

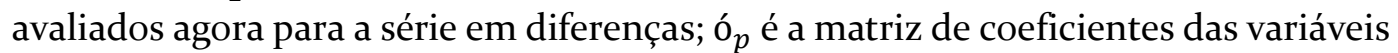
em nível defasadas em um período (representa as propriedades de longo prazo do sistema); ó ${ }_{i}$ dá a dinâmica de curto prazo do sistema; e, por fim, novamente o vetor de resíduos é $\varepsilon_{t}$, que mantém as mesmas propriedades de ruído branco anteriormente citadas.

Se ó $p=0$, então as variáveis não são cointegradas e a relação pode ser reduzida a um vetor autorregressivo nas primeiras diferenças, podendo ter ou não o vetor de interceptos e tendência determinística, assumindo a forma da equação (11):

$$
\Delta Y_{t}=\delta_{0}+\delta_{1} t+\sum_{i=1}^{p-1} \dot{o}_{i} \Delta Y_{t-i}+\varepsilon_{t}
$$

Uma forma de testar se ó $o_{p}=0$ é através da análise de posto, isto é, se o posto de ó $p$ for zero, é possível concluir que o sistema é não estacionário, logo não há

7 Tenham média igual a zero, variância constante e não apresentem correlação serial. 
cointegração entre as variáveis. Porém, se o posto $\left(o_{p}\right) \neq 0$, então há um vetor de cointegração ${ }^{8} \mathrm{e}$, portanto, existe relação de longo prazo entre as variáveis.

Para verificar se posto $\left(o_{p}\right) \neq 0$, ou seja, se existe um vetor de cointegração, analisa-se a estatística do traço de Johansen (1991), definida em sua formulação geral como:

$$
L R=-T \sum_{r+1}^{n} \ln \left(1-\hat{\lambda}_{i}\right)
$$

em que LR é a estatística do teste; o tamanho da amostra é definido como T; r representa a quantidade de vetores do cointegração (nesse caso, pode haver apenas um vetor de cointegração, dado que se está lidando com apenas duas variáveis); $\hat{\lambda}_{i}$, $i=1, \ldots, n$ representa as $\mathrm{n}$ correlações canônicas ao quadrado entre $Y_{t-p}$ e $\Delta Y_{t}$, respeitando ordem decrescente. $\mathrm{O}$ teste é realizado definindo um provável número de vetores de cointegração $(r)$. Se a estatística LR do teste for menor que o valor crítico, não se pode rejeitar $H_{0}$, que pode ser especificada como hipótese de $\mathrm{r}$ ser igual ou menor que determinado número, ou somente igual a um número, no caso de $r=0$.

Uma das etapas importantes no processo de estimação do VAR e implementação do teste acerca da presença de um ou mais vetores de cointegração é a determinação da ordem de defasagem (p) do modelo. Para tanto, pode-se recorrer a critérios de informação como Akaike (AIC), Hannan and Quinn (HQ), Schwarz (SC), ou erro final de previsão (final prediction error - FPE), que são definidos da seguinte forma:

$$
\begin{aligned}
& I C(p)=\log \operatorname{det}\left(\tilde{\Sigma}_{u}(p)\right)+\frac{2}{T} p K^{2}, \\
& H Q(p)=\log \operatorname{det}\left(\tilde{\Sigma}_{u}(p)\right)+\frac{2 \log (\log (T))}{T} p K^{2}, \\
& S C(p)=\log \operatorname{det}\left(\tilde{\Sigma}_{u}(p)\right)+\frac{(\log (T)}{T} p K^{2}, \\
& F P E(p)=\left(\frac{T+p^{*}}{T-p^{*}}\right)^{K} \operatorname{det}\left(\tilde{\Sigma}_{u}(p)\right)
\end{aligned}
$$

em que $\tilde{\Sigma}_{u}(p)=T^{-1} \sum_{t=1}^{T} \hat{u}_{t} \hat{u}_{t}{ }^{\prime} ; p^{*}$ é o número total de parâmetros em cada equação e $p$ determina a ordem de defasagem.

Além da metodologia de Johansen (1991), será realizado o procedimento de análise de cointegração em dois passos Engle-Granger, no qual, em um primeiro momento, é analisada a estacionariedade das séries, de modo que, se elas forem

\footnotetext{
${ }^{8}$ Especificação para o caso em que há duas variáveis $(\mathrm{n}=2)$. Para especificação geral consultar Johansen (1988).
} 
integradas de ordem um (I(1)), pode haver a cointegração, logo, uma relação de longo prazo entre elas. Sendo as séries I(1), são feitas regressões simples entre elas; caso os resíduos dessas regressões forem estacionários (I(o)), tem-se a cointegração entre as variáveis.

Em relação aos testes para o estudo de estacionariedade das séries, serão explicitados alguns dos mais populares e bem recomendados pela literatura para o caso em análise. O primeiro teste a ser utilizado é o Dickey Fuller Aumentado (ADF), que será implementado de modo sequencial na análise de presença/ausência de raiz unitária na série. $O$ teste pode ser utilizado em sua formulação geral, ou com intercepto, ou com tendência:

$$
\begin{aligned}
\Delta Y_{t} & =\alpha+\beta t+\pi Y_{t}+\sum_{i=1}^{m} \gamma_{i} \Delta Y_{t-i}+\varepsilon_{t} \\
\Delta Y_{t} & =\alpha+\pi Y_{t}+\sum_{i=1}^{m} \gamma_{i} \Delta Y_{t-i}+\varepsilon_{t} \\
\Delta Y_{t} & =\pi Y_{t}+\sum_{i=1}^{m} \gamma_{i} \Delta Y_{t-i}+\varepsilon_{t}
\end{aligned}
$$

De acordo com Pfaff (2008) e Enders (2008), o teste é formulado sob as seguintes hipóteses nulas: $H_{0}: \alpha=\beta=\pi=0, H_{0}: \beta=\pi=0, H_{0}: \pi=0$ (partindo da formulação geral para a mais restrita). A última hipótese nula é a de que a série seja um passeio aleatório, então, se rejeitada, ela não possui uma raiz unitária, os valores críticos da estatística do teste em relação a essa hipótese são dados por $\tau_{3}$. A segunda hipótese nula, cujo valor crítico é dado por $\phi_{3}$, é a de que simultaneamente exista uma raiz unitária e que o valor do intercepto seja zero. Por último, a primeira hipótese nula é a de que $\pi=0$, além da inexistência de drift $(\alpha=0)$ e de tendência determinística $(\beta=0)$, seu valor crítico é dado por $\phi_{1}$.

Após a implementação do teste, deve-se averiguar o correlograma dos resíduos, tanto para ele seja validado (nesse caso, os resíduos devem ser não correlacionados), como para a definição do número de defasagens a serem incluídas no teste, uma vez que quanto mais regressores menor o poder do teste ${ }^{9}$.

Ainda, o teste ADF pode ser utilizado para verificação de estacionariedade dos resíduos na metodologia de cointegração de Engle e Granger (1987), cujos valores das áreas de rejeição diferem do caso da análise de estacionariedade usual e podem ser obtidos em Engle e Yoo (1987) e Banerjee et al. (1993).

Outro teste a ser implementado é o Phillips-Perron (PP), que tem uma abordagem diferente do ADF em relação à correlação dos resíduos. A equação base do teste é a mesma do caso de Dickey-Fuller com constante e tendência. Entretanto, utiliza o estimador Newey-West na estimação da matriz de variância robusta. O

${ }^{9}$ Critérios de seleção como AIC e BIC auxiliam nessa tarefa. Ver Pfaff (2008). 
teste emprega uma abordagem não paramétrica em que a rejeição de $H_{0}$ implica a rejeição da hipótese da presença de uma raíz unitária [1].

Por fim, também se fará uso do teste KPSS, desenvolvido por Kwiatkowski et al. (1992). Sua hipótese nula é oposta à do teste ADF, ou seja, é a de que a série seja estacionária. Se o valor da estatística LM do teste for maior que o valor crítico para um dado nível de significância, então pode-se rejeitar a hipótese de estacionaridade a esse nível de significância. Sua formulação é dada por:

$$
Y_{t}=d_{t}+r_{t}+\varepsilon_{t}
$$

em que $d_{t}$ é uma tendência determinística; $r_{t}$ é um passeio aleatório; $\varepsilon_{t}$ é um termo de erro estocástico [2].

\section{Análise Empírica}

A análise empírica da sustentabilidade da dívida pública no Brasil foi realizada para o período de janeiro de 2000 a dezembro de 2017, utilizando algumas séries de dados mensais de variáveis de política fiscal e de monetária. Em relação às variáveis fiscais - receita total e despesa total ${ }^{10}$ - recorreu-se a séries disponíveis no site do Tesouro Nacional ${ }^{11}$. Quanto às variáveis monetárias - IPCA, taxa de juros (Selic) e meio circulante $\left(M_{1}\right)$ - foi utilizada a base de dados do Instituto de Pesquisa Econômica Aplicada (Ipea) ${ }^{12}$.

\subsection{Comportamento do Déficit Público}

Como afirmado na seção 3, o comportamento da série do déficit público é um elemento chave na avaliação de sustentabilidade da dívida pública. Conforme a equação (3), ele é dado pela diferença entre a despesa total e a receita total do governo incluindo a senhoriagem, sua trajetória é apontada na Figura 1.

Até meados de 2014, o déficit seguia um movimento ligeiramente estável. No entanto, a partir daí, nota-se o aumento da variabilidade da série, com saltos de grande amplitude. Essa mudança pode ser resultante de uma possível alteração estrutural, especialmente em virtude da diminuição da arrecadação no período póscrise, como pode ser visto em Afonso (2015) e Afonso e de Castro (2016).

\footnotetext{
${ }^{10}$ A série de despesas totais foi acrescida das transferências por repartição de receitas (também disponível na base do Tesouro Nacional), dado que são receitas que a União arrecada, porém, são destinadas a estados, municípios e fundos constitucionais.

${ }_{11}$ Disponível em: http://www.tesourotransparente.gov.br/visualizacoes/series-temporais.

${ }^{12} M_{1}$ corresponde ao papel moeda em poder do público acrescido dos depósitos à vista. Foram utilizadas as séries $M_{1}$ e Selic para fim de período. Todas as séries podem ser acessadas em: http://www.ipeadata.gov.br.
} 
A tabela 1 apresenta os resultados do teste ADF para o déficit público. Note que os valores da estatística t são menores em módulo que os valores críticos de $\tau_{3}$ e $\phi_{3}$, Sendo assim, não se pode rejeitar as hipóteses de presença de raiz unitária isoladamente e de que não existe tendência dado que há raiz unitária.

Então, é realizado um novo teste ADF, porém, em sua formulação sem o termo de tendência determinística, cujos resultados também são apresentados na Tabela 1. Como o valor da estatística de $\tau_{2}$ é positivo, não se pode descartar a hipótese de presença de raiz unitária na série. Além disso, como a estatística para $\phi_{1}$ é inferior aos valores críticos, deve-se refazer o teste sem o termo de tendência determinística e de intercepto.

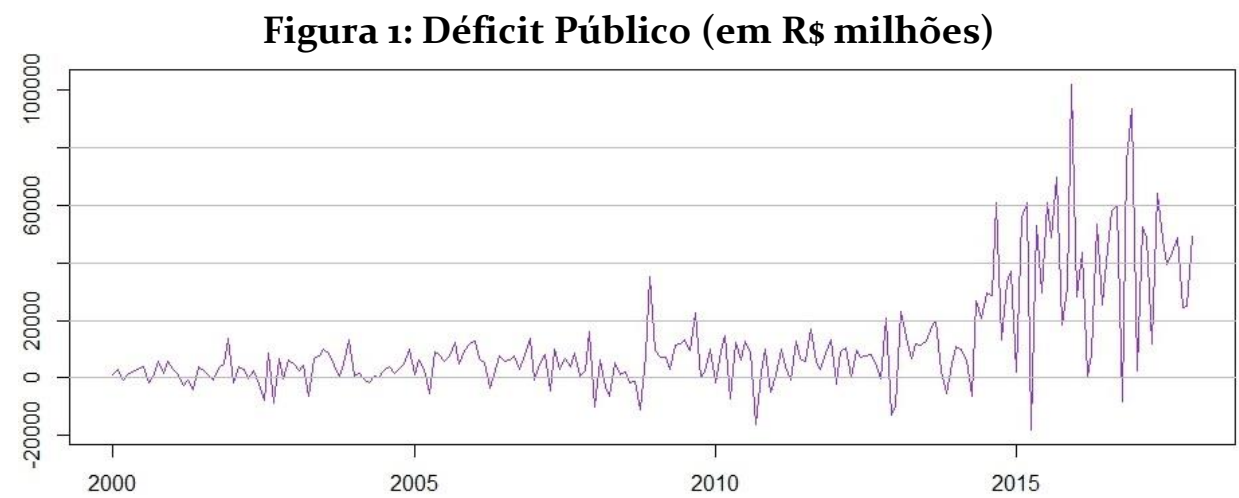

Fonte: Elaboração dos autores com base nos dados do Tesouro Nacional (2018).

Por fim, o resultado do teste ADF sem intercepto e sem tendência foi positivo para estatística $t$, indicando, portanto, a presença de raiz unitária na série. Os resíduos dos testes ADF não apresentaram autocorrelação, sendo utilizados 12 lags como defasagem máxima para os testes.

Tabela 1: Teste ADF (1) - Déficit Público

\begin{tabular}{c|c|c|c|c}
\hline \hline Valores críticos & $\mathbf{1 \%}$ & $\mathbf{5 \%}$ & $\mathbf{1 0} \%$ & Estatística \\
\hline$\tau_{3}$ & $-3,99$ & $-3,43$ & -3.13 & $-\mathbf{1 , 3 1}$ \\
\hline$\phi_{2}$ & 6,22 & 4,75 & 4,07 & 1,72 \\
\hline$\phi_{3}$ & 8,43 & 6,49 & 5,47 & 1,65 \\
\hline$\tau_{2}$ & $-3,46$ & $-2,88$ & $-2,57$ & 0,04 \\
\hline$\phi_{1}$ & 6,52 & 4,63 & 3,81 & 0,92 \\
\hline$\tau_{1}$ & $-3,46$ & $-2,88$ & $-2,57$ & 0,87 \\
\hline \hline
\end{tabular}

Fonte: Elaborado pelos autores, utilizando o pacote urca do software R-Studio. 
Para confirmação dos resultados encontrados no teste ADF, foi calculado também o teste KPSS para o déficit público. Seus resultados apontaram para a rejeição da hipótese de estacionaridade da série. O valor da estatística LM do teste foi de 0,965 , enquanto o valor crítico para $1 \%$ de significância foi de 0,739 . Portanto, como a estatística do teste foi maior que o seu valor crítico, é rejeitada a hipótese de estacionariedade da série, fato que ratifica os resultados do teste ADF.

Desse modo, pode-se concluir que há evidências para a não estacionariedade da série do déficit público, isto é, das primeiras diferenças da dívida pública. Considerando esses resultados, receitas e despesas totais do governo não devem cointegrar, o que será analisado a seguir.

\subsection{Análise de Cointegração - Gastos e Receitas Totais do Governo}

O ponto de partida para análise de cointegração entre receitas e despesas do governo é o estudo acerca da estacionariedade da taxa real de juros. Conforme descrito na metodologia, essa é uma condição necessária a fim de que a abordagem de cointegração entre as variáveis fiscais possa evidenciar a hipótese de sustentabilidade da dívida pública brasileira.

Tabela 2: Teste ADF (2) - Taxa Real de Juros

\begin{tabular}{c|c|c|c|c}
\hline \hline Valores críticos & $\mathbf{1 \%}$ & $\mathbf{5 \%}$ & $\mathbf{1 0} \%$ & Estatística \\
\hline$\tau_{3}$ & $-3,99$ & $-3,43$ & -3.13 & $-5,54$ \\
\hline$\phi_{2}$ & 6.22 & 4,75 & 4,07 & 10,27 \\
\hline$\phi_{3}$ & 8,43 & 6,49 & 5,47 & 15,40 \\
\hline \hline
\end{tabular}

Fonte: Elaborado pelos autores, utilizando o pacote urca do software R-Studio.

A taxa real de juros foi obtida descontando-se a inflação, medida pelo IPCA, dos valores da série mensal da Selic para fim de período. A figura 2 mostra a evolução da taxa de juros real para o período analisado. A média mensal da taxa real de juros foi de $0,56 \%$ para os anos em estudo.

O primeiro teste a ser aplicado foi o teste ADF. É importante destacar que os valores críticos do teste variam de acordo com o tamanho da amostra e a especificação do mesmo. Como se trata de uma série temporal longa, com 216 observações, o critério de seleção de lags utilizado foi o Critério de Informação Bayesiano (BIC). Também foi definido o número de 12 lags como o valor máximo para o critério de seleção, levando em conta uma possível sazonalidade na série. 
Figura 2: Taxa Real de Juros (\%)

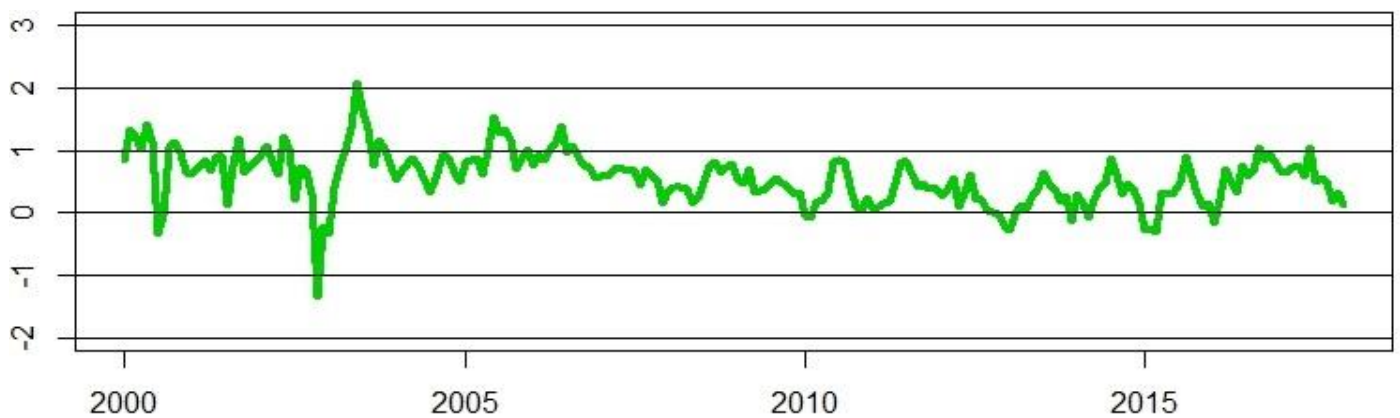

Fonte: Elaboração dos autores com base em dados do IPEA (2018).

Uma vez que a estatística do teste foi menor que os valores críticos de $\tau_{3}$, o teste aponta para rejeição da hipótese presença de raiz unitária para todos níveis de significância. Após a sua realização, notou-se a presença de autocorrelação significativa em apenas uma defasagem mais distante do correlograma de resíduos da série. Então, para uma análise mais precisa também se recorreu ao teste KPSS e Phillips-Perron, que, como discutido na seção 3, contorna esse problema da autocorrelação residual ocorrido no teste ADF.

Figura 3: Receitas Totais do Governo - R (em R\$ milhões)

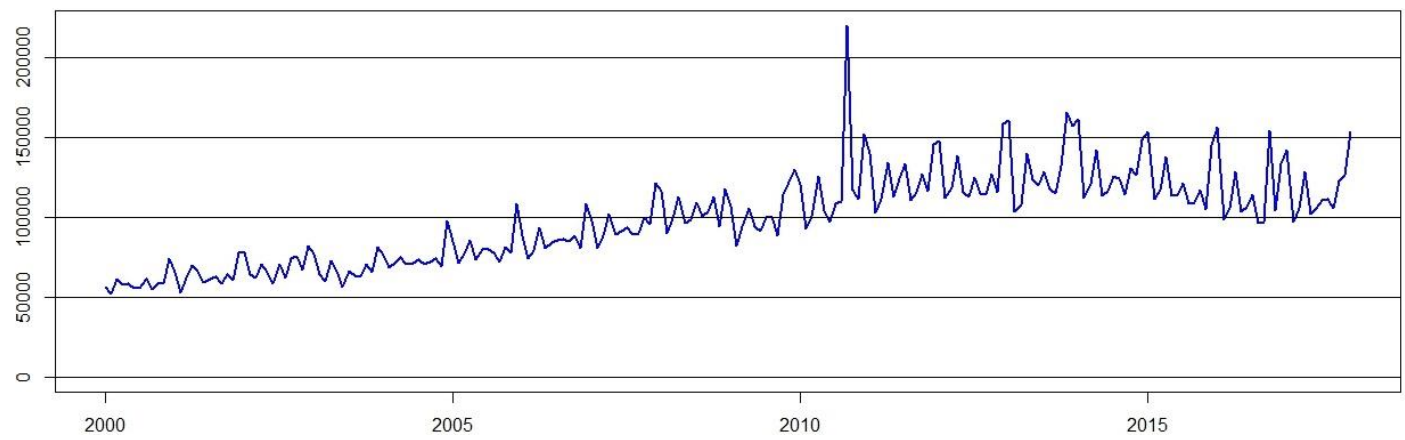

Fonte: Elaboração dos autores com base em dados do Tesouro Nacional (2018).

O resultado do teste Phillips-Perron (PP) também apontou para a rejeição da hipótese nula de presença de raiz unitária. O valor da estatística $\mathrm{PP}^{13}$ foi de $-6,4105$, com trucagem de 14 lags e p-valor inferior a o,o1. Já o teste KPSS apresentou estatística de o,127, com valor crítico de o,146 ao nível de 5\% de significância, de

\footnotetext{
${ }^{13}$ Nesse caso a ordem de truncagem é definida automaticamente na utilização da função PP.test() do pacote stats do R-studio e retorna apenas o valor da estatística, a trucagem e o p-valor.
} 
modo que não se pode rejeitar a hipótese de estacionariedade da série. Logo, há evidências suficientes para não rejeitar a hipótese de estacionariedade da taxa real de juros, o que permite a análise de cointegração das variáveis fiscais.

No que tange as variáveis ficais tem-se que a receita total $\left(R_{t}\right)$ corresponde ao total da arrecadação tributária advinda de impostos e de contribuições, além de concessões, dividendos, doações, convênios, entre outras fontes da Administração Pública Federal acrescida da senhoriagem.

Em relação à receita com emissão de moeda tomou-se o imposto inflacionário como proxy para senhoriagem (S), com a alíquota dada pelo IPCA sobre o valor real de $\mathrm{M}$, dada sua aproximação de valores, especialmente quando a taxa de inflação e a taxa de expansão da base monetária são semelhantes, tal escolha também foi feita por Silva e Gamboa (2011) e é comum na literatura relacionada. Contudo, quando adicionada a senhoriagem à receita total, ela corresponde em média a apenas o,65\% dos valores assumidos por $R_{t}$, optou-se, ainda assim, por fazer a análise com a senhoriagem, pois mesmo não tendo grande relevância na receita total, ela torna o modelo mais completo, exemplo disso também é visto em Silva e Gamboa (2011), que chegaram ao mesmo resultado em sua análise de cointegração entre despesas e receitas do governo, considerando ou não a senhoriagem.

Figura 4: Despesas totais do Governo - G (em R\$ milhões)

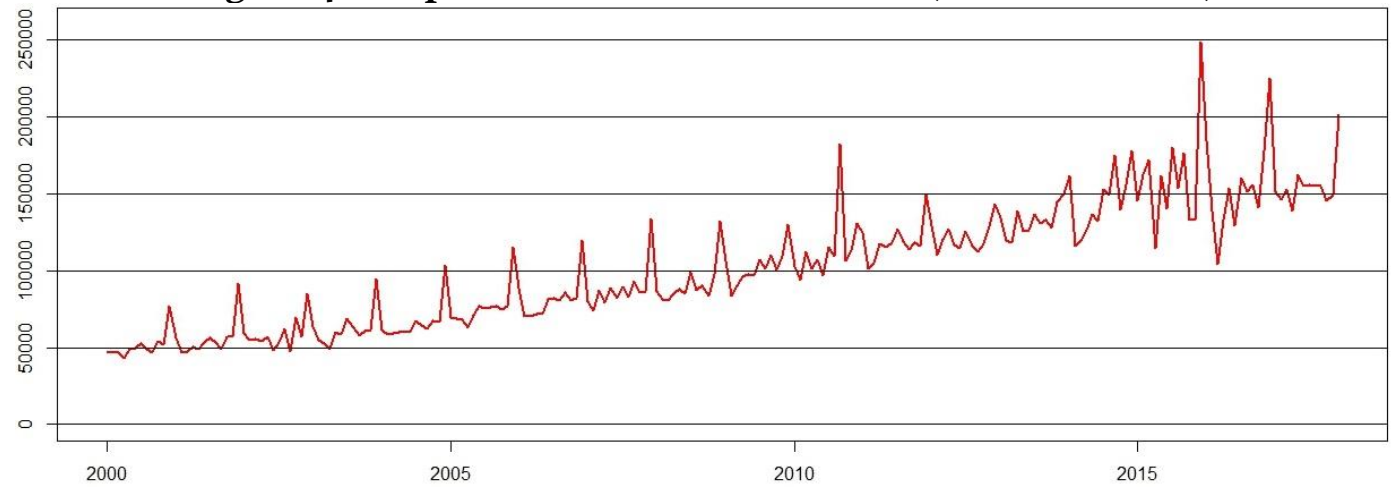

Fonte: Elaboração dos autores com base em dados do Tesouro Nacional (2018).

Enquanto a despesa total $(G)$ é formada pelo dispêndio com custeio e com investimentos, com serviços e com encargos da dívida mobiliária e da dívida interna e externa, benefícios sociais e previdenciários, entre outros gastos da Administração Pública, acrescidos das transferências por repartição de poder.

O primeiro ponto na análise das variáveis fiscais é o estudo da estacionariedade das séries e suas primeiras diferenças, feita com o auxílio do teste ADF e também do teste KPSS. Novamente, seguindo o fluxograma de Pfaff (2008) é 
realizado teste ADF. Como já destacado anteriormente, primeiro utiliza-se o teste em sua versão mais abrangente e, se necessário, retira-se o termo de tendência determinística do teste. Depois disso, ele é refeito com a nova formulação. Por fim, caso seja necessário, pode-se retirar o termo de intercepto e aplicar o teste novamente.

Tabela 3: Teste ADF (3) - Variáveis Fiscais

\begin{tabular}{c|c|c|c|c|c}
\hline \hline & \multicolumn{3}{|c|}{ Nível de significância } & \multicolumn{2}{c}{ Estatística } \\
\hline Valores críticos & $\mathbf{1 \%}$ & $\mathbf{5 \%}$ & $\mathbf{1 0 \%}$ & $\mathbf{G}$ & $\mathbf{R}$ \\
\hline$\tau_{3}$ & $-3,99$ & $-3,43$ & $-3,13$ & $-2,51$ & $-0,36$ \\
\hline$\phi_{2}$ & 6,22 & 4,75 & 4,07 & 9,98 & 2,85 \\
\hline$\phi_{3}$ & 8,43 & 6,49 & 5,47 & 3,22 & 1,24 \\
\hline$\tau_{2}$ & $-3,46$ & $-2,88$ & $-2,57$ & 0,02 & $-1,57$ \\
\hline$\phi_{1}$ & 6,52 & 4,63 & 3,81 & 11,42 & 4,27 \\
\hline$\tau_{1}$ & $-2,58$ & $-1,95$ & $-1,62$ & 2,01 & - \\
\hline \hline
\end{tabular}

Fonte: Elaborado pelos autores, utilizando o pacote urca do software R-Studio

Como as estatísticas do teste para variáveis fiscais são superiores aos valores críticos de $\tau_{3}$, não se pode descartar a presença de raiz unitária para as duas séries. Além disso, para os dois casos verifica-se que as estatísticas são inferiores aos valores críticos de $\phi_{3}$, o que indica que não pode ser rejeitada a hipótese de que não há tendência, dado que a série possui raiz unitária. Assim, é realizado um novo teste sem a presença de tendência determinística.

Note que o valor das estatísticas $t$ das variáveis fiscais foi superior ao valor de $\tau_{2}$, então, não se pode rejeitar a hipótese da presença de raiz unitária para as séries. Ainda, para a hipótese de presença de intercepto, dado que há raiz unitária, o valor da estatística do teste se mostrou maior que os valores críticos $\left(\phi_{1}\right)$ para $G_{t}$, o que leva à rejeição dessa hipótese a $1 \%$ de significância e à conclusão de que essa série possui raiz unitária. Ao mesmo tempo, para $R_{t}$ rejeitou-se tal hipótese apenas a $10 \%$ de significância, o que indica a necessidade de aplicação da última formulação do teste $\mathrm{ADF}$ (sem tendência e intercepto) a essa série apenas por precaução.

Os resultados do teste ADF, em sua formulação sem o termo de tendência determinística e intercepto para a série $R_{t}$ também foram incluídos na tabela 3 . Como foi apurado um valor maior que zero para as estatísticas e o teste é unilateral, não se rejeita a hipótese nula de raiz unitária. Portanto, de acordo com Pfaff (2008), pode-se concluir que as duas séries de variáveis fiscais possuem raiz unitária. Os resíduos dos testes $\mathrm{ADF}$ não apresentaram nenhuma correlação serial para 12 lags (número de defasagens ao qual o teste foi programado).

Dado que não houve autocorrelação dos resíduos para os testes ADF, foi utilizado apenas o teste KPSS para corroboração da hipótese da presença de raiz unitária. Os resultados do teste KPSS apontam para a rejeição da hipótese nula de as 
séries serem estacionárias em nível, uma vez que as estatísticas do teste para as duas variáveis são maiores que o valor crítico de $\mu$ a $1 \%$ de significância. Além disso, a estatística do teste indica a rejeição da hipótese da série $R_{t}$ ser estacionária em tendência a $1 \%$ de significância, enquanto essa hipótese é rejeitada para $G_{t}$ a $5 \%$ de significância. O que leva a confirmação de que a séries fiscais, possuem raiz unitária, ou seja, são não estacionárias.

Tabela 4: Teste KPSS - Variáveis Fiscais

\begin{tabular}{c|c|c|c|c|c}
\hline \hline & \multicolumn{3}{|c|}{ Nível de significância } & \multicolumn{2}{c}{ Estatística } \\
\hline Valores críticos & $\mathbf{1 0} \%$ & $\mathbf{5 \%}$ & $\mathbf{1 \%}$ & $\mathbf{G}$ & $\mathbf{R}$ \\
\hline$\tau$ & 0,119 & $\mathbf{0 , 1 4 6}$ & $\mathbf{0 , 2 1 6}$ & 0,171 & 0,252 \\
\hline$\mu$ & 0,347 & 0,463 & 0,739 & 1,528 & 1,397 \\
\hline \hline
\end{tabular}

Fonte: Elaborado pelos autores, utilizando o pacote urca do software R-Studio.

Agora será analisada a estacionariedade da primeira diferença das séries fiscais. O primeiro teste aplicado foi o teste ADF, pela Tabela 5 nota-se que os valores da estatística t são bem inferiores aos valores críticos $\tau_{3}$, assim, para as séries de diferenças das variáveis fiscais é rejeitada a hipótese nula de presença de raiz unitária. Ainda, não há presença de autocorrelação dos resíduos do teste para o número de lags ${ }^{14}$ utilizado.

Tabela 5: Teste ADF (4) - Primeiras Diferenças das Variáveis Fiscais

\begin{tabular}{c|c|c|c|c|c}
\hline \hline & \multicolumn{3}{|c|}{ Nível de significância } & \multicolumn{2}{c}{ Estatística } \\
\hline Valores críticos & $\mathbf{1 \%}$ & $\mathbf{5 \%}$ & $\mathbf{1 0 \%}$ & $\mathbf{\Delta G}$ & $\mathbf{\Delta}$ \\
\hline$\tau_{3}$ & $-3,99$ & $-3,43$ & $-3,13$ & $-14,03$ & $-11,13$ \\
\hline$\phi_{2}$ & 6,22 & 4,75 & 4,07 & 65,68 & 41,42 \\
\hline$\phi_{3}$ & 8,43 & 6,49 & 5,47 & 98,51 & 62,10 \\
\hline \hline
\end{tabular}

Fonte: Elaborado pelos autores, utilizando o pacote urca do software R-Studio.

Para confirmar os resultados gerados pelo ADF, também foi calculado o teste KPSS para as séries de diferenças das variáveis fiscais. Como os valores da estatística LM foram bastante inferiores aos valores críticos, então, não se pode rejeitar a hipótese de que as diferenças das séries fiscais sejam estacionárias em nível. Logo, pode-se concluir que as primeiras diferenças das séries fiscais são estacionárias e, portanto, as séries fiscais são I(1).

Considerando que as séries fiscais são estacionárias em primeira diferença, foi estimada uma regressão das receitas contra as despesas totais do governo.

\footnotetext{
${ }^{14}$ Para as primeiras diferenças, o teste ADF também foi especificado com 12 lags e critério de seleção "BIC".
} 
Posteriormente, seguindo a metodologia de Engle e Granger (1987), foi realizado o teste $\mathrm{ADF}$ sobre os resíduos da regressão. $\mathrm{O}$ valor da estatística t que foi de $-1,18$, dentro da área de não rejeição da hipótese da presença de raiz unitária ${ }^{15}$. Também foi feita a regressão das despesas contra as receitas totais do governo. $\mathrm{O}$ valor da estatística $t$ foi de -0,4291, que também é superior aos valores críticos para reijeição de $H_{0}$. Dessa forma, é rejeitada a hipótese de cointegração entre arrecadação e gastos totais do governo é rejeitada.

Tabela 6: Teste KPSS - Diferenças das Variáveis Fiscais

\begin{tabular}{c|c|c|c|c|c}
\hline \hline & \multicolumn{3}{|c|}{ Nível de significância } & \multicolumn{2}{c}{ Estatística } \\
\hline Valores críticos & $\mathbf{1 0} \%$ & $\mathbf{5 \%}$ & $\mathbf{1 \%}$ & $\mathbf{\Delta G}$ & $\mathbf{\Delta}$ \\
\hline$\tau$ & $\mathbf{0 , 1 1 9}$ & $\mathbf{0 , 1 4 6}$ & $\mathbf{0 , 2 1 6}$ & 0,094 & 0,051 \\
\hline$\mu$ & 0,347 & 0,463 & 0,739 & 0,043 & 0,050 \\
\hline \hline
\end{tabular}

Fonte: Elaborado pelos autores, utilizando o pacote urca do software R-Studio.

Por fim, é analisada a cointegração das variáveis pela metodologia de Johansen (1991). Nesse caso, o primeiro passo para análise de cointegração é a aplicação dos critérios para definição da ordem de defasagem do modelo VAR (p), cujos resultados são apresentados na tabela 7 .

Tabela 7: Critérios de Informação

\begin{tabular}{c|c|c|c}
\hline \hline Akaike (AIC) & Hannan and Quinn (HQ) & Schwarz (SC) & Final Prediction Error (FPE) \\
\hline 3 & 3 & 3 & 3 \\
\hline \hline
\end{tabular}

Fonte: Elaborado pelos autores, utilizando o pacote vars do software R-Studio.

Os critérios de informação foram calculados, levando em conta a possível presença de tendência determinística e de intercepto em sua formulação, além de incluir a possibilidade de sazonalidade com dummies para os 12 meses do ano. ${ }^{16}$ Para todos os critérios de seleção a ordem de defasagem ótima para VAR é igual a três, sendo esta escolhida para especificação do VAR para análise cointegração via teste do traço e autovalor de Johansen.

Os testes do traço e autovalor de Johansen indicam a não rejeição da hipótese da inexistência de um vetor de cointegração para o modelo. Uma vez que os valores da estatística do teste foram menores que os níveis de significância em todos os casos, indicando a não rejeição das hipóteses nulas. Sendo assim, pode-se concluir que receita e despesa total não apresentam cointegração. O que confirma o resultado

\footnotetext{
${ }^{15}$ Os valores críticos do teste ADF quando se avalia a estacionaridade dos resíduos para hipótese de cointegração são diferentes do caso normal e podem ser consultados em Engle e Yoo (1987).

${ }^{16}$ Tais opções são possíveis utilizando a função VARselect () do pacote vars no R, com defasagem máxima de 30 lags.
} 
obtido através da metodologia de Engle e Granger (1987), ratificado a evidência de não haver relação de longo prazo entre arrecadação e gasto do governo federal.

Tabela 8: Testes de Johansen

\begin{tabular}{c|c|c|c|c|c|c|c|c}
\hline \hline & \multicolumn{4}{|c|}{ Teste do Traço } & \multicolumn{3}{c}{ Teste do Autovalor } \\
\hline $\boldsymbol{H}_{\mathbf{0}}$ & Estatística & $\mathbf{1 0 \% *}$ & $\mathbf{5 \%}^{* *}$ & $\mathbf{1 \%} \mathbf{*}^{* *}$ & Estatística & $\mathbf{1 0 \% *}$ & $\mathbf{5 \%}^{* *}$ & $\mathbf{1 \%}^{* * *}$ \\
\hline$r \leq 0$ & 1,59 & 6,50 & 8,18 & 11,65 & $\mathbf{1 , 6 1}$ & 6,49 & 8,19 & 11,67 \\
\hline$r=0$ & 12,94 & 15,66 & 17,95 & $\mathbf{2 3}, 52$ & 11,35 & 12,91 & 14,90 & 19,19 \\
\hline \hline
\end{tabular}

Fonte: Elaborado pelos autores, utilizando o pacote vars do software R-Studio.

Voltando a análise do processo de endividamento, sua evolução para níveis mais elevados, insustentáveis do ponto de vista da teoria econômica, pode causar uma série de prejuízos aos fundamentos macroeconômicos do país. Como apontando por Kumar e Baldacci (2010), a elevação da razão dívida/produto afeta a taxa de juros estrutural de uma economia, elevando os custos com pagamento de juros e reforçando a aceleração do endividamento público. E segundo Reinhart e Rogoff (2010), Checherita e Rother (2012) e Woo e Kumar (2015) pode impactar negativamente o crescimento econômico, o que torna a tarefa de reequilíbrio fiscal ainda mais árdua, pela diminuição de receita.

Fatores como a queda de arrecadação vivenciada principalmente após 2014 e o constante aumento dos gastos com o custeio da administração pública são candidatos a explicar as evidências de uma possível insustentabilidade do regime fiscal brasileiro. Além disso, estaria ocorrendo um processo de estabilização tardia, no qual, segundo Alesina e Drazen (1991), grupos de interesse postergam as políticas de ajuste fiscal, dado que as medidas deste os prejudicariam devido algum interesse privado comum. E esse retardo na implementação de políticas de estabilização reforçaria a trajetória de elevação do estoque de dívida pública

\section{Considerações Finais}

A sustentabilidade do processo de endividamento público, ou ainda, a satisfação da restrição orçamentaria intertemporal do governo é um requisito básico para estabilidade das condições macroeconômicas, segundo a ótica do equilíbrio ricardiano. A sua não satisfação pode afetar a dinâmica de uma economia de diversos modos, como tem mostrado a literatura macroeconômica recente. Assim, é de suma importância que com alguma frequência se retome ao tema e que se refaça a análise da sustentabilidade fiscal de uma determinada economia.

O ponto de partida para a análise de sustentabilidade do processo de endividamento brasileiro foi o estudo da estacionariedade da série de déficit público, lembrando que no seu cálculo foi subtraída a receita auferida por meio de senhoriagem. Os testes ADF e KPSS realizados com a formulação indicada para esse 
caso, apontaram para a rejeição da hipótese de estacionariedade da série, o que, em termos econômicos, indica a violação da condição de equilíbrio intertemporal do governo.

Com a finalidade de ratificar os resultados obtidos na análise anterior, também foi construído um modelo para avaliação da cointegração entre receitas e gastos do governo, que poderia indicar uma relação de longo prazo entre essas variáveis caso a hipótese de cointegração se confirmasse, o que validaria a hipótese de estacionariedade do déficit público, acarretando, portanto, na sustentabilidade do processo de endividamento do governo. Porém, os resultados da análise apontaram para a não cointegração entre receitas e despesas do governo, corroborando o quadro de um regime fiscal insustentável do ponto de vista ricardiano, como apontado pela análise anterior.

Um outro ponto interessante foi a diminuição da importância da senhoriagem na composição da receita total do governo, representando em média o,65\% da arrecadação se tomado o imposto inflacionário como proxy para tal variável. Se comparado a estudos que analisaram a sustentabilidade da dívida pública para períodos anteriores, principalmente para épocas em que o país convivia com taxas altas de inflação, como os casos encontrados em Pastore (1994) e Gamboa (2005), sua relevância na composição da receita do governo é bem menor em comparação a vários períodos nos estudos citados. Porém a análise de Silva e Gamboa (2011) já apontava para diminuição de importância da senhoriagem tendo em vista o controle da inflação que se viu em períodos mais recentes.

Os resultados da presente análise de sustentabilidade fiscal do país apontaram para um desvio do quadro de um regime fiscal equilibrado. O que difere de estudos anteriores realizados com o mesmo intuito para períodos diferentes, como Pastore (1994) e Silva e Gamboa (2011), nos quais a avaliação apontava para um regime que respeitava a restrição orçamentária intertemporal do governo, ou seja, satisfazia a hipótese ricardiana do orçamento equilibrado. Ademais, o presente estudo traz evidências para um tópico muito discutido no meio acadêmico e mercado em tempos recentes e a avaliação empírica vai no caminho de reforçar as suspeitas do descontrole fiscal brasileiro.

\section{Referências}

AFONSO, J. R. Antecipando os números oficiais da arrecadação federal: resultados para junho de 2015. 2015.

AFONSO, J. R.; DE CASTRO, K. P. Termômetro tributário no brasil: queda de temperatura em 2016 como em 1992. Caderno Virtual, v. 1, n. 34, 2016. 
ALESINA, A.; DRAZEN, A. Why Are Stabilizations Delayed? A Political Economy Model. American Economic Review, no 81. 1991. DOI:

https://doi.org/10.1177/o010414003262072

BANERJEE, A. Co-integration, error correction, and the econometric analysis of non-stationary data. OUP Catalogue, 1993. DOI: 10.1093/0198288107.001.0001

BOHN, $\mathrm{H}$. Budget balance through revenue or spending adjustments?: Some historical evidence for the United States. Journal of monetary economics, v. 27, n. 3, p. 333-359, 1991. DOI: https://doi.org/10.1016/0304-3932(91)90013-E BOHN, H. The behavior of US public debt and deficits. The Quarterly Journal of Economics, v. 113, n. 3, p. 949-963, 1998. DOI:

https://doi.org/10.1162/o03355398555793

$\mathrm{BOHN}, \mathrm{H}$. Are stationarity and cointegration restrictions really necessary for the intertemporal budget constraint? Journal of Monetary Economics, v. 54, n. 7, p. 1837-1847, 2007. DOI: https://doi.org/10.1016/j.jmoneco.2006.12.012

BOHN, H. The sustainability of fiscal policy in the United States. Sustainability of Public Debt, p. 15-49, 2008. DOI: 10.7551/mitpress/9780262140980.003.0002

CHECHERITA-WESTPHAL, C.; ROTHER, P. The impact of high government debt on economic growth and its channels: An empirical investigation for the euro area. European Economic Review, v. 56, n. 7, p. 1392-1405, 2012. DOI: https://doi.org/10.1016/j.euroecorev.2012.06.007

ENDERS, W. Applied econometric time series. John Wiley \& Sons, 2008.

ENGLE, R. F.; GRANGER, C. WJ. Co-integration and error correction: representation, estimation, and testing. Econometrica: journal of the Econometric Society, p. 251-276, 1987. DOI: 10.2307/1913236

ENGLE, R. F.; YOO, B. S. Forecasting and testing in co-integrated systems. Journal of Econometrics, v. 35, n. 1, p. 143-159, 1987. DOI: https://doi.org/10.1016/03044076(87)90085-6

GAMBOA, U. R. Dívida pública brasileira, default e a "Nova Equivalência Ricardiana”: Um exercício cliométrico do Brasil-Império a Época Atual. IPE/USP, p. 20, 2005.

GARCIA, M.; RIGOBON, R. A risk management approach to emerging market's sovereign debt sustainability with an application to Brazilian data. National Bureau of Economic Research, 2004. 
GHOSH, A. R. Fiscal fatigue, fiscal space and debt sustainability in advanced economies. The Economic Journal, v. 123, n. 566, 2013. DOI:

https://doi.org/10.1111/ecoj.12010

HAMILTON, J. D.; FLAVIN, M. On the limitations of government borrowing: A framework for empirical testing. 1985.

HAKKIO, C. S.; RUSH, M. Is the budget deficit “too large?”. Economic Inquiry, v. 29, n. 3, p. 429-445, 1991. DOI: https://doi.org/10.111//j.1465-7295.1991.tboo837.X

HAUG, A. A. Has federal budget deficit policy changed in recent years? Economic Inquiry, v. 33, n. 1, p. 104-118, 1995. DOI: https://doi.org/10.1111/j.14657295.1995.tbo1849.x

ISSLER, J. V.; LIMA, L. R. R. O. Como se equilibra o orçamento do governo no Brasil? Aumento de receitas ou corte de gastos? 1998.

JOHANSEN, S. Statistical analysis of cointegration vectors. Journal of Economic Dynamics and Control, v. 12, n. 2-3, p. 231-254, 1988. DOI:

https://doi.org/10.1016/0165-1889(88)90041-3

JOHANSEN, S. Estimation and hypothesis testing of cointegration vectors in Gaussian vector autoregressive models. Econometrica, p. 1551-1580, 1991. DOI: $10.2307 / 2938278$

KUMAR, M. S.; BALDACCI, E. Fiscal deficits, public debt, and sovereign bond yields. International Monetary Fund, 2010. DOI:

http://dx.doi.org/10.5089/9781455202188.001

KWIATKOWSKI, D. Testing the null hypothesis of stationarity against the alternative of a unit root: How sure are we that economic time series have a unit root? Journal of Econometrics, v. 54, n. 1-3, p. 159-178, 1992. DOI:

https://doi.org/10.1016/0304-4076(92)90104-Y

LIMA, L. R. R. de O; SIMONASSI, A. G. Dinâmica não-linear e sustentabilidade da dívida pública brasileira. 2005 .

LUPORINI, V. Sustainability of the Brazilian fiscal policy and central bank independence. Revista Brasileira de Economia, v. 54, n. 2, p. 201-226, 200o. DOI: https://doi.org/10.1590/So034-71402000000200004

PASTORE, A. C. Déficit Público, a Sustentabilidade do Crescimento das Dívidas Interna e Externa, Senhoriagem e Inflação: Uma Análise do Regime Monetário Brasileiro. Brazilian Review of Econometrics, v. 14, n. 2, p. 177-234, 1994. DOI: http://dx.doi.org/10.1266o/bre.v14n21994.2972 
PFAFF, B. Analysis of integrated and cointegrated time series with R. Springer Science \& Business Media, 2008.

REINHART, C. M.; ROGOFF, K. S. Growth in a Time of Debt. American Economic Review, v. 100, n. 2, p. 573-78, 2010. DOI: 10.3386/w15639

ROCHA, F. Long-run limits on the Brazilian government debt. Revista Brasileira de Economia, v. 51, n. 4, p. 447-470, 1997.

SARGENT, T. J.; WALLACE, N. Rational expectations and the theory of economic policy. Journal of Monetary Economics, v. 2, n. 2, p. 169-183, 1976. DOI: https://doi.org/10.1016/0304-3932(76)90032-5

SILVA, R.; GAMBOA, U. R. Regime fiscal e sustentabilidade da dívida pública brasileira - 1986 a 2006. Revista Gestão \& Políticas Públicas, v. 1, n. 1, 2011.

TANNER, E.; RAMOS, A. M. Fiscal sustainability and monetary versus fiscal dominance: evidence from Brazil, 1991-2000. Applied Economics, v. 35, n. 7, p. 859-873, 2003. DOI: https://doi.org/10.108o/o003684032000056832

TANNER, E.; SAMAKE, I. Probabilistic sustainability of public debt: a vector autoregression approach for Brazil, Mexico, and Turkey. IMF Staff Papers, v. 55, n. 1, p. 149-182, 2008.

TREHAN, B.; WALSH, C. E. Common trends, the government's budget constraint, and revenue smoothing. Journal of Economic Dynamics and Control, v. 12, n. 23, p. 425-444, 1988. DOI: https://doi.org/10.1016/o165-1889(88)90048-6

WALSH, C. E. Monetary Theory and Policy. Volume 1 of MIT Press Books. 2010. WOO, J.; KUMAR, M. S. Public debt and growth. Economica, v. 82, n. 328, p. 705739, 2015.

WOODFORD, M. Fiscal requirements for price stability. National Bureau of Economic Research, 2001. DOI: 10.2307/2673890

WOODFORD, M. Price-level determinacy without control of a monetary aggregate. In: Carnegie-Rochester Conference Series on Public Policy. NorthHolland, 1995. p. 1-46. DOI: https://doi.org/10.1016/o167-2231(95)90033-0 